A C T A C H E M C A S C A N D I N A V I C A $17 \quad(1963) 801-804$

\title{
Gas Chromatographic Analysis of a Mixture of Acetaldehyde, Acetone, Vinyl Acetate, Acetic Acid, Paraldehyde, Acetic Anhydride, and Ethylidene Diacetate
}

\author{
BENGT SMITH and JOSEF DAHLÉN
}

Institutionen för Organisk Kemi, Chalmers Tekniska Högskola, Göteborg, Sweden

\begin{abstract}
A qualitative and quantitative gas chromatographic analysis of the mixture specified in the heading has been made using stationary phases of the tetraalkylsilane type.
\end{abstract}

$I_{a}^{\mathrm{n}}$

connection with an investigation of methods for the preparation of vinyl acetate carried out in this laboratory it was desired to obtain a qualitative as well as a quantitative analysis of the multicomponent mixture mentioned above. Preliminary experiments, using wet analytical methods, indicated that the analytical work would be very time-consuming and that the values obtained for some of the components would be of low accuracy. Since it was essential to get a reasonably rapid analysis with a good overall accuracy, it was decided to try to solve this analytical problem by means of gas chromatography.

In Table 1 the formulas, boiling points, and molecular weights of the compounds present in the mixture are given. It is seen that, except for acetone and acetic acid, there is an even spread of the molecular weights. This fact suggests the possibility of separating the mixture using a nonpolar stationary phase. Although acetone and acetic acid have nearly the same molecular weight, there is hardly any risk of a coincidence of the peaks of these two compounds. Because of the greater polarity of acetic acid it will be less volatile than acetone, also on a nonpolar stationary phase, partly due to an influence of the solid support. In fact it was subsequently found that the volatility of acetic acid on nonpolar stationary phases was considerably less than that of acetone (cf. below).

One peculiarity that was observed at an early stage of this investigation was a certain malformation of the acetic anhydride peak and of the valley between it and the preceding acetic acid peak. The reason for this seemed to be a partial transformation of acetic anhydride into acetic acid during the 
Table 1. Components in the mixture to be analyzed.

\begin{tabular}{llcc}
\hline Name & Formula & B.p. ${ }^{\circ} \mathrm{C}$ & Molecular weight \\
\hline Acetaldehyde & $\mathrm{CH}_{3} \mathrm{CHO}$ & 21 & 44 \\
Acetone & $\mathrm{CH}_{3} \mathrm{COCH}{ }_{3}$ & 56.5 & 58 \\
Vinyl acetate & $\mathrm{CH}_{2}=\mathrm{CHOCOCH}$ & 86 \\
Acetic acid & $\mathrm{CH}_{3} \mathrm{COOH}$ & 72 & 60 \\
Paraldehyde & $\left(\mathrm{CH}_{3} \mathrm{CHO}\right)_{3}$ & 118 & 132 \\
Acetic anhydride & $\left(\mathrm{CH}_{3} \mathrm{CO}\right)_{2} \mathrm{O}$ & 124 & 102 \\
Ethylidene diacetate & $\mathrm{CH}_{3} \mathrm{CH}(\mathrm{OCOCH})_{2}$ & 140 & 146 \\
\hline
\end{tabular}

passage of the column. It might be due to moisture in the carrier gas or in the column packing material and also to active centres containing hydroxyl groups in the solid support and stationary phase. It was found, for example, that when acetic anhydride was run on a polyethylene glycol column an unusually large decomposition occurred.

Although provisions were made to remove moisture from the carrier gas and the column packing and also to neutralize active centres in the solid support by treatment with hexamethyldisilazane or acetic anhydride, they did not wholly prevent the decomposition, and neither did a change of the solid support from Chromosorb or Celite to Teflon. Thus, it must be concluded that the cause of the decomposition could not be removed completely by the measures taken. When very accurate analyses are wanted, this transformation might impair the analysis values appreciably. However, in our case, it was not deemed necessary to take any special precautions in order to increase the accuracy.

As mentioned previously, there seemed to be good prospects for separating the components of the mixture using a nonpolar stationary phase because of the even spread of the molecular weights. In spite of this, it proved to be difficult to get the required spacing of the peaks using conventional nonpolar
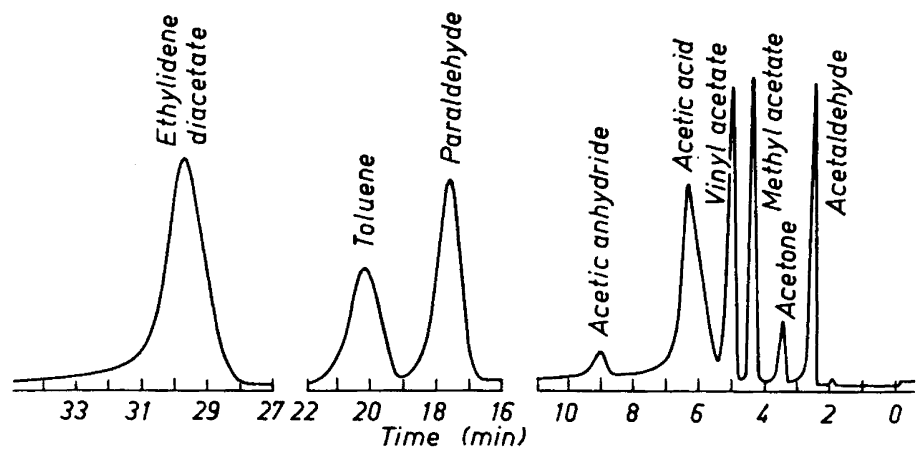

Fig. 1. Analysis of a mixture of acetaldehyde, acetone, vinyl acetate, acetic acid, acetic anhydride, paraldehyde and ethylidene diacetate. Internal standards: methyl acetate and toluene. Columns: tetraamylsilane, $2 \mathrm{~m}$, plus dimethyldioctylsilane, $2 \mathrm{~m}$. Temperature $95^{\circ} \mathrm{C}$, flow of $\mathrm{He} 40 \mathrm{ml} / \mathrm{min}$. 
Table 2. Analysis values of a mixture of known composition.

\begin{tabular}{lccc}
\hline Compound & True value & Obtained value & \% Error \\
\hline Acetaldehyde & & & \\
Acetone & 4.13 & 4.05 & -1.9 \\
Vinyl acetate & 0.55 & 0.52 & -5.5 \\
Acetic acid & 23.0 & 22.9 & -0.4 \\
Acetic anhydride & 23.9 & 25.4 & +6.3 \\
Paraldehyde & 46.1 & 44.7 & -3.0 \\
Ethylidene diacetate & 1.75 & 1.87 & +6.9 \\
\hline
\end{tabular}

stationary phases, e.g. squalane, paraffin oil, apiezons and silicones. Previously, tetraamylsilane has been shown at this laboratory to be an unusually nonselective stationary phase (cf. Ref. ${ }^{1}$ ) and application of this substrate to the present problem gave the required solution of the problem (cf. Fig. 1). In fact, the tetraamylsilane column was used in conjunction with another tetraalkylsilane column of similar performance, namely one containing dimethyldioctylsilane as the stationary phase. However, this arrangement was made just for convenience because the two columns were available at this laboratory. We are convinced that a single tetraamylsilane column of sufficient length would have given the same result as the combination actually used.

A suitable analysis temperature was found to be $95^{\circ} \mathrm{C}$. This temperature is somewhat high with respect to the volatility of the tetraalkylsilanes employed. On this account the percentage of stationary phase in the columns diminishes during use, thus resulting in a shortening of the elution times and in an impaired separation of the components in the mixture. Thus, when the columns had been in daily use for 6 months, the total elution time had become diminished from $32 \mathrm{~min}$ to $19 \mathrm{~min}$. However, the columns were still usable. A higher boiling tetraalkylsilane would undoubtedly have been a better choice as a stationary phase in the present case.

The quantitative analysis was performed using the internal standard method. Because of the broad distillation range of the mixture, resulting in narrow peaks at the beginning of the chromatogram and broad peaks at the end, two standard substances were utilized. For the first range, including acetaldehyde, acetone and vinyl acetate, methyl acetate was employed as internal standard and, for the second range, comprising the remainder of the components in the mixture, toluene was used. However, since the amount of acetic acid was of minor interest, the percentage of this compound was calculated as a difference, thereby simplifying the calibration work.

The analysis in the first range was based on a comparison between the peak heights while, in the second range, a comparison between the areas under the peaks was made ( $c f$. experimental section). In Table 2, some representative analysis values are given.

\section{EXPERIMENTAL}

Columns. The columns were made of aluminium tubing of $4 \mathrm{~mm}$ internal diameter and $2 \mathrm{~m}$ length. The stationary phase (20 parts) was applied in petroleum ether solution on to the solid support, Celite $545,60-100$ mesh (80 parts). The solvent was evaporated and

Acta Chem. Scand. 17 (1963) No. 3 
the dry powder was then evenly packed in the column. For the preparation of tetraamylsilane, cf. Ref. ${ }^{2}$

Procedure. A Perkin-Elmer Vapour Fractometer, Model 116 E, was used. The mixture was run at $95^{\circ}$ and a flow rate of helium of $40 \mathrm{ml} / \mathrm{min}$ was employed.

Preliminary to the quantitative analysis of the mixture, calibration curves were obtained. For the first three compounds in the chromatogram (cf. Fig. 1), methyl acetate was employed as internal standard. Mixtures containing known amounts of methyl acetate, acetaldehyde, acetone, and vinyl acetate were made up and chromatographed. The heights of the peaks were measured and, for each compound, the ratio of the peak height to the peak height of methyl acetate plotted as a function of the corresponding weight ratio. A straight line through the origin was obtained in each case within the region investigated.

For the determination of acetic anhydride, paraldehyde and ethylidene diacetate, toluene was used as internal standard. The calibration procedure was identical with that previously described with the exception that, in this case, the ratio of the areas under the peaks were used instead of the ratio of the peak heights. The areas were obtained by multiplying the peak heights by half the band widths. Straight calibration lines were obtained also in this case.

To analyze a mixture of unknown composition, a known weight of it was mixed with known amounts of methyl acetate and toluene. The mixture was chromatographed, the appropriate ratios were calculated from the chromatogram and finally the weights of the components in the mixture obtained using the calibration curves. Acetic acid was not included in the calibration. The content of it in the mixture was calculated by taking the difference between the total weight of the mixture and the sum of the weights of the components determined by the internal standard method.

Acknowledgement. This investigation has been supported by Skånska Ättikfabriken AB, Perstorp.

\section{REFERENCES}

1. Smith, B., Ohlson, R. and Larson, G. Acta Chem. Scand. 17 (1963) 436.

2. Smith, B. Acta Chem. Scand. 13 (1959) 877.

Received September 18, 1962.

Acta Chem. Scand. 17 (1963) No. 3 